\title{
An experimental investigation on effective parameters of batch impregnation systems: a case study on $\mathrm{Pt}-\mathrm{Sn} / \mathrm{Al}_{2} \mathrm{O}_{3}$ catalyst
}

\author{
Maryam Takht Ravanchi ${ }^{1} \cdot$ Shokoufeh Mehrazma $^{1} \cdot$ Saeed Sahebdelfar $^{1}$
}

Received: 4 October 2017 / Accepted: 13 February 2018 / Published online: 26 February 2018

(c) The Author(s) 2018. This article is an open access publication

\begin{abstract}
The adsorption of hexachloroplatinic acid on Sn-impregnated $\gamma$-alumina support in the presence of the competitive chloride ion, as a step in preparation of multi-metallic Pt-based catalyst (such as $\mathrm{Pt}-\mathrm{Sn} / \mathrm{Al}_{2} \mathrm{O}_{3}$ ), was studied. The transient adsorption data were obtained by studying the impregnation of $\mathrm{Sn} / \mathrm{Al}_{2} \mathrm{O}_{3}$ with $\mathrm{H}_{2} \mathrm{PtCl}_{6}$ in an external recycle packed-bed impregnation system. The effect of important parameters such as $\mathrm{pH}$ of the impregnating solution, circulation flow rate, and height/ diameter ratio of support bed on competitive adsorption was studied. It was observed that upon increasing $\mathrm{pH}$ and decreasing circulation rate, the rate of Pt adsorption as well as axial non-uniformity along the bed was increased. On the other hand, a time lag was observed in bulk adsorbate concentration in certain runs which was attributed to deviation from well-mixed contacting pattern being necessary for a uniform catalyst product. This could be minimized by increasing the recycling flow rates and using appropriate amounts of competitive ion concentration.
\end{abstract}

Keywords Pt-Sn $/ \mathrm{Al}_{2} \mathrm{O}_{3} \cdot$ Catalyst synthesis $\cdot$ Wet impregnation $\cdot$ Competitive adsorption $\cdot$ Recycle reactor

\section{Introduction}

Supported catalysts are used in a variety of industrial processes. High surface area, low amount of active component, and high mechanical and thermal stability are some of the advantages of these catalysts $[4,6,10,20]$. The performance of a catalytic process is intimately related to its catalyst design. In general, a supported catalyst consists of an active component (e.g., a metal or metal oxide) which is deposited on a carrier material such as silica or alumina. The use of different supports causes an obvious change in the distribution of metallic particles and the interfacial character between the metal and the support. It is found that relatively large surface area and uniform pore size distribution of the support are favorable for the dispersion of metallic particles [21]. There are four categories of intra-particle metal profiles: uniform, egg-yolk (the active component is deposited at the support center), egg-shell (the active component layer is concentrated close to the support external surface), and egg-white [17]. The

Maryam Takht Ravanchi

m.ravanchi@npc-rt.ir; maryamravanchi@gmail.com

1 Catalyst Research Group, Petrochemical Research and Technology Company, National Petrochemical Company, P.O. Box 14358-84711, Tehran, Iran choice of the optimal metal profile in the support is determined by the required activity and selectivity, and by other characteristics of the chemical reactions (kinetics and mass transfer). Egg-shell catalysts are advantageous in the case of fast reactions with strong diffusion restrictions [5] while egg-yolk catalysts are advantageous in the case of reaction restrictions, or intense abrasion, attrition, or poisoning [18]. Uniform and egg-white metal profiles can also be optimal for certain applications [14]. Although catalyst preparation and catalytic processing have been investigated for many years, many aspects of the various catalyst manufacturing steps are still not fully understood, and the design of catalysts in industry is usually based on trial and error.

The deposition of active components on the support by impregnation is an important step in the preparation of supported catalysts. Two techniques can be applied for impregnation via the liquid phase $[7-9,13]$. "Dry" impregnation is employed in the case of weak adsorption strength, using a sufficient volume of precursor solution to fill the total pores of the carrier batch. In "wet" impregnation, which is commonly used in the case of strong adsorption strength, impregnating solution volume is much larger than the support pore volume. The metal compound diffuses from the solution into the carrier particle pores where it is adsorbed. In this case, capillary forces do not participate and the 
distribution of metal in the support is due to diffusion and adsorption.

In preparation of $\mathrm{Pt} / \mathrm{Al}_{2} \mathrm{O}_{3}$ catalyst, when large alumina particles are impregnated with a solution of hexachloroplatinic acid $\left(\mathrm{CPA}, \mathrm{H}_{2} \mathrm{PtCl}_{6}\right)$ alone, usually an "egg-shell" profile is achieved because CPA adsorption is so rapid that the diffusion of the solute into the pores controls the rate. By introducing a competitor adsorbate, the platinum tends to penetrate deeper into the interior of the support. Competitors compete with metal ions for being adsorbed on the support surface by adsorption on active sites first and then driving the metal ions to the subsurface layers [19]. Two kinds of competitive adsorbate have been reported. When using a limited amount of polybasic organic acid, i.e., citric or tartaric acid as a competitive agent, a catalyst with an "egg-white" or "egg-yolk" type distribution may be achieved. On the other hand, when acetic, chloro-acetic, nitric, or hydrochloric acid is used, the platinum does not distribute in an "egg-white" or "egg-yolk" type, but tends to form an uniform or broadened "egg-shell" type distribution. The competitor ion, $\mathrm{Cl}^{-}$, influences the acid property, dispersity, and agglomeration of $\mathrm{Pt}$ and the interaction between metal and support. It also keeps the Pt particles from sintering and lowers carbon deposition [11].

The previous studies on the effects of competitive ion were largely focused on intra-particle Pt distribution assuming the uniformity of the product $[2,15,17]$. This is a reasonable assumption in lab-scale works but could not be the case in large-scale catalyst production especially when strong precursor-support interactions do exist. This necessitates considering further preparation parameters such as external mass transfer and flow pattern. The objective of the present research is to investigate the effective parameters in adsorption of metal precursor on the support and in inter-particle metal distribution in wet impregnation of a shaped support. Using an external recycle impregnation system, the effect of $\mathrm{pH}$ of impregnating solution, circulation flow rate, and height/ diameter $(L / D)$ ratio of support bed on competitive adsorption was studied. Bimetallic $\mathrm{Pt}-\mathrm{Sn} / \mathrm{Al}_{2} \mathrm{O}_{3}$ catalyst which is used for paraffin dehydrogenation in commercial petrochemical plants is selected as a case study.

\section{Experimental}

\section{Materials}

Commercial $\gamma-\mathrm{Al}_{2} \mathrm{O}_{3}$ (BET surface area: $205 \mathrm{~m}^{2} / \mathrm{g}$, pore volume: $0.78 \mathrm{~cm}^{3} / \mathrm{g}$, particle diameter: $1.8 \mathrm{~mm}$ ), was used as the support. Hexachloroplatinic acid $\left(\mathrm{H}_{2} \mathrm{PtCl}_{6} \cdot 6 \mathrm{H}_{2} \mathrm{O}\right)$ and tin chloride $\left(\mathrm{SnCl}_{2} \cdot 2 \mathrm{H}_{2} \mathrm{O}\right)$ from Merck Co. were used as precursor source of $\mathrm{Pt}$ and $\mathrm{Sn}$, respectively, and hydrochloric acid $(\mathrm{HCl})$ from Merck Co. was used as the competitor.

\section{Catalyst preparation procedure}

On the $\gamma$-alumina support, as the first step, Sn was impregnated using an acidic solution of $\mathrm{SnCl}_{2}$ and wet impregnation technique in rotary instrument at $40{ }^{\circ} \mathrm{C}$, followed by drying at $120{ }^{\circ} \mathrm{C}$ for $12 \mathrm{~h}$ and calcination at $530{ }^{\circ} \mathrm{C}$ for $2 \mathrm{~h}$ in wet air under controlled temperature increments of $5{ }^{\circ} \mathrm{C} /$ min rate.

In a subsequent second step, Pt was impregnated by wet impregnation in a solution containing $\mathrm{H}_{2} \mathrm{PtCl}_{6}$ and $\mathrm{HCl}$ at $25{ }^{\circ} \mathrm{C}$ using a closed-loop flow system. The impregnation set-up consisted of an upward-flow double-wall external recycle quartz reactor, two peristaltic pumps for circulating impregnating solution from the solution vessel into the reactor and an on-line UV-Vis apparatus for kinetic evaluation of platinum adsorption. The space below the support particles bed ( $30 \mathrm{~g}, L / D=3$ and 7 ) was packed with quartz particles (mesh 10) to ensure proper distribution of fluid flow through the bed. The $\mathrm{pH}$ value of the impregnating solution was adjusted to a specific value by the addition of $\mathrm{HCl}(37 \%)$. The $\mathrm{pH}$ value was measured with Metrohm 744 $\mathrm{pH}$ meter. More detailed specification of the set-up can be found elsewhere [17].

The channeling in the reactor could be neglected as the radial aspect ratio (bed diameter to catalyst particle diameter) was $>15$. The axial aspect ratio, i.e., the ratio of catalyst bed length to catalyst particle diameter, was $>30$ and hence the dispersion effects can also be neglected $[1,15]$.

\section{Metal content analysis}

UV-Vis spectra of impregnation solution in the solution vessel were recorded with a PG Instrument T90+ UV-Vis spectrometer. The spectra backgrounds were recorded with both sample and reference cuvettes containing the matrix used to make up the sample.

Platinum concentration in the impregnating solution was determined spectrophotometrically by recycling the solution to a quartz cell and measuring the absorbance at $450 \mathrm{~nm}$ against the reagent blank (appropriate amount of $\mathrm{HCl}$ in $\mathrm{H}_{2} \mathrm{O}$ ). The UV/Vis spectrophotometer was set to record an absorbance spectrum every $120 \mathrm{~s}$, for the duration of the particular experiment. The analyte concentration was calculated from a calibration curve constructed by taking different concentrations of platinum. Two calibration curves were used for measuring platinum concentration in two different ranges [Eqs. (1) and (2)]:

$$
\begin{gathered}
0.02-0.89\left(\mathrm{mmol}_{\mathrm{Pt}} / L_{\text {solution }}\right): y=0.05221 x-0.00048 \\
\left(R^{2}=0.999\right),
\end{gathered}
$$

$0.78-8.18\left(\mathrm{mmol}_{\mathrm{Pt}} / L_{\text {solution }}\right): y=0.0501 x-0.0152\left(R^{2}=0.999\right)$, 
where $y$ and $x$ are absorbance and concentration, respectively.

The process for measuring the chloride concentration was the same as platinum. Reagents to make colorful solution were ammonium iron (II), sulfate dodecahydrate, and mercury (II) thiocyanate. The concentration of chloride in the impregnating solution was determined by recycling the solution to the quartz cell and measuring the absorbance at $563 \mathrm{~nm}$ against the reagent blank (appropriate amount of ammonium iron (II) sulfate dodecahydrate and mercury (II) thiocyanate in water). The analyte concentration was calculated from a calibration curve constructed by taking different concentrations of chloride in the presence of reagents. The calibration curve used for the measurement of chloride concentration in the range of $1.12-7.84\left(\mathrm{mmol}_{\mathrm{Cl}} / L_{\text {solution }}\right)$ was as Eq. (3):

$y=0.00431 x-0.00026\left(R^{2}=0.999\right)$,

where $y$ and $x$ are absorbance and concentration, respectively.

\section{Results and discussion}

\section{Effect of $\mathrm{pH}$ of the impregnation solution}

The addition of $\mathrm{HCl}$ into impregnating solution affects both adsorption and distribution of Pt in catalyst granules through decreasing $\mathrm{pH}$ and introducing competitive chloride ion and accordingly their catalytic performance with the latter being a more important factor [16]. As a consequence, either $\mathrm{pH}$ or chloride ion concentration can be used to characterize the $\mathrm{HCl}$ level, and thus its effect on adsorption process. As platinum is a precious metal, the $\mathrm{pH}$ of the impregnating solution must be optimized such that maximum platinum adsorption with uniform distribution is achieved.

In order to investigate the influence of competitor ion, three $\mathrm{pH}$ values $(1.3,1.4$, and 1.5$)$ were considered for impregnating solution. Figure 1 illustrates the effect of $\mathrm{pH}$ on the adsorption of $\mathrm{Pt}$ and $\mathrm{Cl}$ as a function of time. A higher $\mathrm{pH}$ (that is, lower $\mathrm{Cl}^{-}$competitive ion concentration) increased the rate of adsorption and total ( equilibrium) adsorption of Pt on the support was occurred. This can be accounted for by availability of more free adsorption sites for the adsorption of $\mathrm{PtCl}_{6}{ }^{2-}$ ions from the precursor solution at lower competitor concentrations despite a decrease in positive surface charge by increasing the $\mathrm{pH}$ (the iso-electric point of alumina is about 7.0-9.0 [16]).

The retention of $\mathrm{Cl}^{-}$ion and the relative rate of its adsorption, on the other hand, were decreased with increasing $\mathrm{pH}$ (Fig. 1b) which could be due to the competition of more chloride ions for the limited adsorption sites. The concentration of chloride ions decreased with time on stream after passing a maximum at about 20 min of adsorption and then leveled out. It could largely be due to consecutive hydrolysis
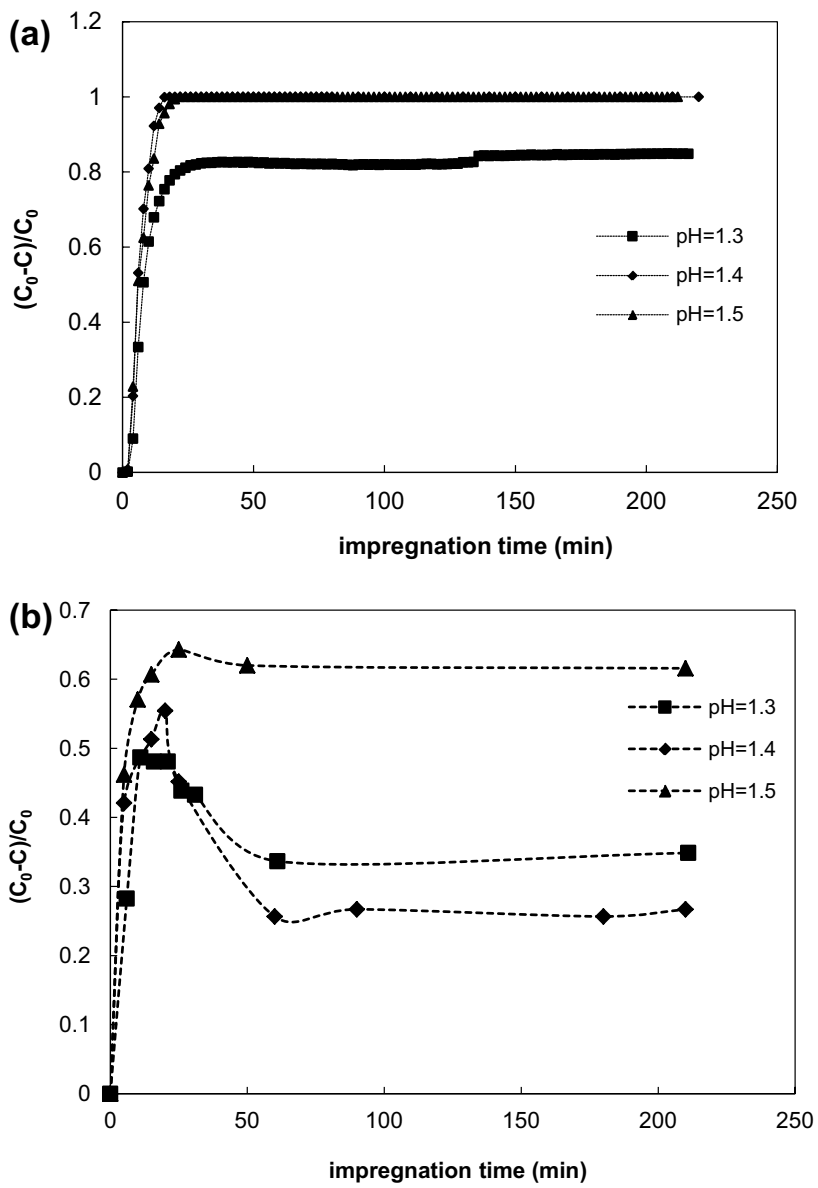

Fig. 1 Variations of impregnation solution concentration as a function of impregnation time at different $\mathrm{pH}$ values for $\mathrm{Pt}-\mathrm{Sn} / \mathrm{Al}_{2} \mathrm{O}_{3}$ catalyst; a platinum, b chlorine (support bed $L / D=7$, circulation flow rate $=15 \mathrm{~mL} / \mathrm{min}$ )

of the adsorbed $\mathrm{PtCl}_{6}{ }^{2-}$ species (Eq. (4) [16]) rather than desorption of the adsorbed $\mathrm{Cl}^{-}$.

$\mathrm{PtCl}_{6-n}^{2-}+\mathrm{H}_{2} \mathrm{O} \Leftrightarrow \mathrm{PtCl}_{5-n}(\mathrm{OH})^{2-}+\mathrm{H}^{+}+\mathrm{Cl}^{-}$.

Table 1 summarizes the $\mathrm{Pt}$ and $\mathrm{Cl}$ precursor concentrations in initial and final impregnating solution as well as the final $\mathrm{Pt}$ adsorption for different $\mathrm{pH}$ values.

It was reported that low $\mathrm{pH}$ and high chloride concentration shifts the coordination toward the chloride [12]. Using UV-Vis-diffuse reflectance spectroscopy, Masesen et al. [12] provided evidence for the partial substitution of halide ligands by oxygen-containing ligands when $\mathrm{H}_{2} \mathrm{PtCl}_{6}$ interacted with $\gamma-\mathrm{Al}_{2} \mathrm{O}_{3}$ surfaces. So, the chlorine concentration passes through a minimum. On the other hand, the $\mathrm{Cl}: \mathrm{O}$ ligand ratio of the complex ions in the solution drops as they adsorb on to the support [12]. The final $\mathrm{pH}$ value of the impregnating solution is higher than that of the initial solution. The decreasing adsorption with increasing final $\mathrm{pH}$ can be explained by the decreasing positive charge density at the 
Table 1 The effect of $\mathrm{pH}$ in catalyst synthesis $\left(\mathrm{Pt}-\mathrm{Sn} / \mathrm{Al}_{2} \mathrm{O}_{3}\right.$ catalyst)

\begin{tabular}{|c|c|c|c|c|c|c|}
\hline \multirow[t]{2}{*}{$\mathrm{pH}$} & \multicolumn{2}{|c|}{$\begin{array}{l}\text { Platinum } \\
\text { concentration } \\
(\mathrm{mmol} / \mathrm{L})\end{array}$} & \multicolumn{2}{|c|}{$\begin{array}{l}\text { Chlorine } \\
\text { concentration } \\
(\mathrm{mmol} / \mathrm{L})\end{array}$} & \multirow[t]{2}{*}{$\begin{array}{l}\text { Platinum } \\
\text { adsorption } \\
(\%)\end{array}$} & \multirow[t]{2}{*}{ Description } \\
\hline & Initial & Final $^{\mathrm{a}}$ & Initial & Final $^{\mathrm{a}}$ & & \\
\hline 1.3 & 7.0 & 1.2 & 109 & 71 & 83 & A uniform support bed color was observed \\
\hline 1.4 & 7.0 & 0.0 & 81 & 46 & 100 & A uniform support bed color was observed \\
\hline 1.5 & 7.0 & 0.0 & 70 & 28 & 100 & A non-uniform support bed color was observed \\
\hline
\end{tabular}

${ }^{a}$ After 220 min on stream alumina surface as the solution $\mathrm{pH}$ approaches the value of the iso-electric point.

A better visualization of $\mathrm{Cl}$ and $\mathrm{Pt}$ adsorption behavior could be obtained by plotting the adsorption of one adsorbate against the other at the same impregnation time. Figure 2 shows such plots for various $\mathrm{pH}$ values. In $\mathrm{pH}$ value of 1.3 , the fractional adsorption of both adsorbates was nearly the same at earlier times on stream, but subsequently, that of $\mathrm{Cl}^{-}$became smaller and the retention of $\mathrm{Pt}$ approached to about 0.8 (Fig. 2a). At higher pH values of 1.4 and 1.5, in contrast, the adsorption of $\mathrm{Cl}^{-}$was nearly equilibrated when only $20 \%$ of the Pt had been absorbed. Over longer adsorption times, the Pt adsorption also approached to equilibrium

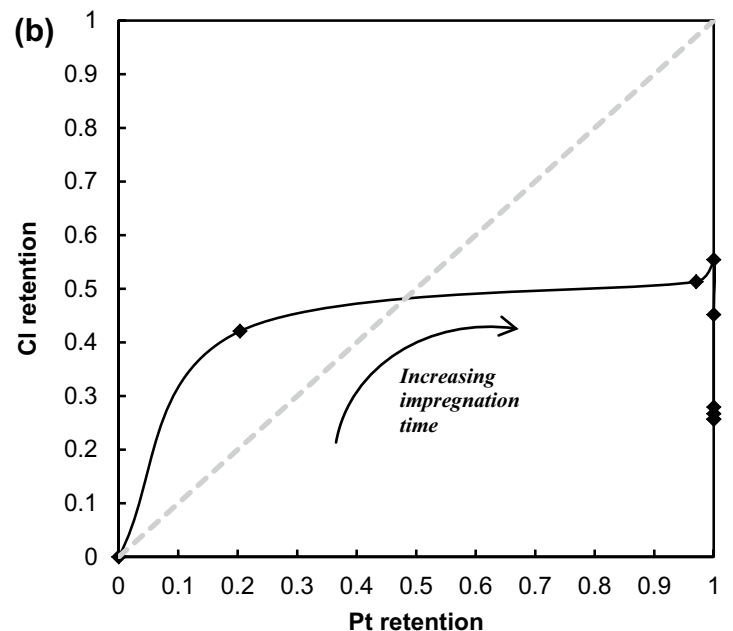

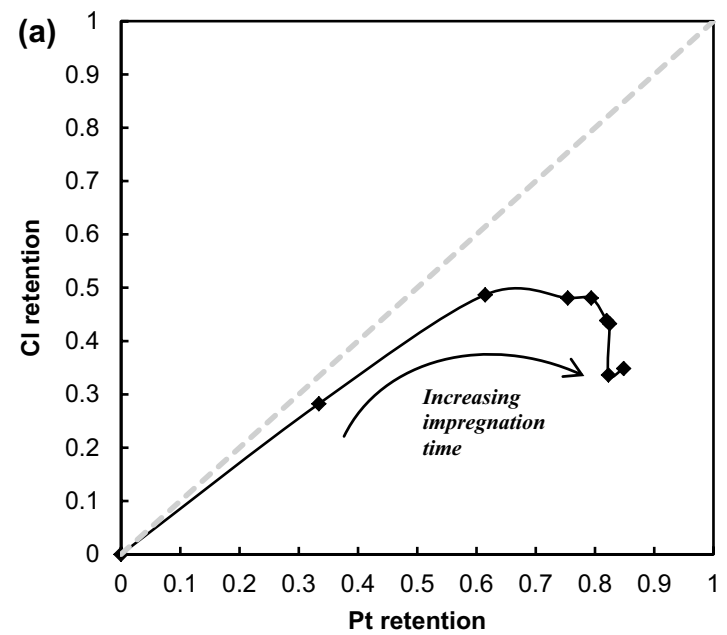

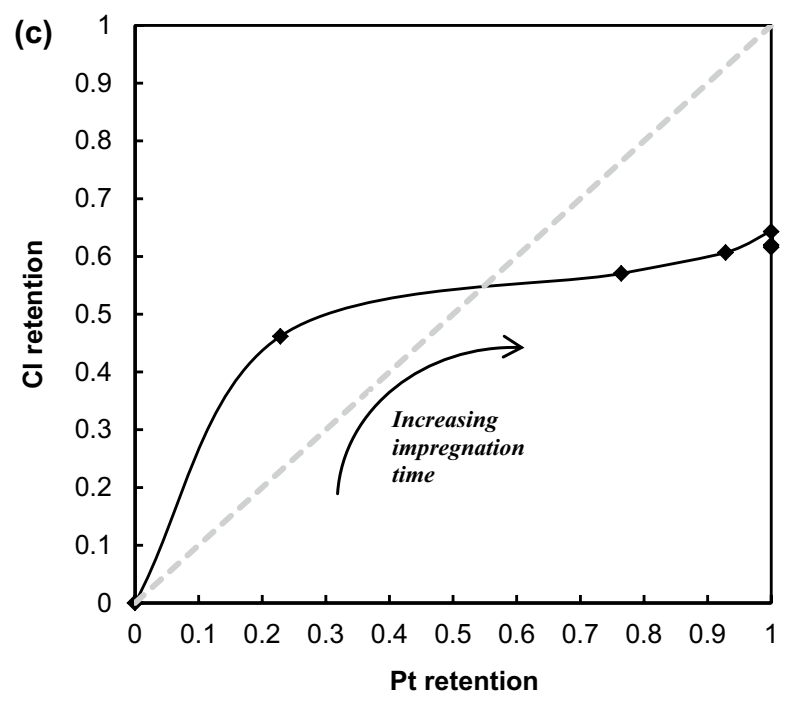

Fig. 2 Plots of $\mathrm{Cl}$ adsorption versus that of $\mathrm{Pt}$ at a $\mathrm{pH} 1.3, \mathbf{b} \mathrm{pH} 1.4, \mathbf{c} \mathrm{pH} 1.5$ (support bed $L / D=7$, circulation flow rate $=15 \mathrm{~mL} / \mathrm{min}$ ) 
after which some chloride ion was released into the impregnating solution as noted above.

It can be shown that the slope of the curves at any point in Fig. 2 is given by

Slope $=\frac{C_{\mathrm{Pt}, 0}}{C_{\mathrm{Cl}, 0}}\left(\frac{r_{\mathrm{Cl}}}{r_{\mathrm{Pt}}}\right)$,

or,

$\frac{r_{\mathrm{Cl}}}{r_{\mathrm{Pt}}}=$ slope $\times\left(\frac{C_{\mathrm{Cl}, 0}}{C_{\mathrm{Pt}, 0}}\right)$,

where $C_{\mathrm{Pt}, 0}$ and $C_{\mathrm{Cl}, 0}(\mathrm{~mol} / \mathrm{L})$ are the initial concentration of CPA and chloride ions, respectively, and $r(\mathrm{~mol} /(\mathrm{kg} \mathrm{s}))$ is the adsorption rate of the respective ions per support weight. According to Table 1, the initial concentration of chloride competitor ion was one order of magnitude larger than that of CPA. Thus, from Fig. 2a and Table 1, the initial slope and the initial concentration ratios were 0.84 and 16 , respectively, from which the initial rate of adsorption of $\mathrm{Cl}$ was ca. 13 times that of CPA at $\mathrm{pH} 1.3$. This could be largely due to the much higher bulk concentration of the former, according to Langmuir adsorption kinetics. The adsorption rate ratios are smaller (ca. 4.5) for initial pH of 1.4 and 1.5 which could be due to decreased competitive adsorption of $\mathrm{Cl}^{-}$at higher $\mathrm{pH}$ values. However, with increasing time on stream, the rate of CPA adsorption might become larger than that of $\mathrm{Cl}$ despite still much higher chloride ion concentration, which could be attributed to thermodynamic equilibrium limitation for the latter as implied by Fig. 1 .

The criteria used in selection of the appropriate $\mathrm{pH}$ value were that a uniform longitudinal color (or no color gradient) along the bed of support was observed after impregnation and platinum was adsorbed at its highest amount. During impregnation, the deep yellow impregnating solution decolorizes while the white support granules turn from creamy yellow to yellow according to the level of Pt precursor adsorbed. As a consequence, the color gradient along the bed can be conveniently used for visual and qualitative monitoring of adsorption performance. Therefore, based upon these criteria:

- $\mathrm{pH} 1.3$ is not appropriate as it resulted in fairly low platinum uptake from impregnating solution (Table 1).

- Although, at pH 1.5 platinum was adsorbed completely, but a uniform bed of catalyst in the impregnation reactor was not obtained after the impregnation was finished. Hence, $\mathrm{pH} 1.5$ is not the suitable choice.

- The optimum pH value is 1.4 at which both maximum platinum adsorption and a uniform bed of catalyst after impregnation were achieved.
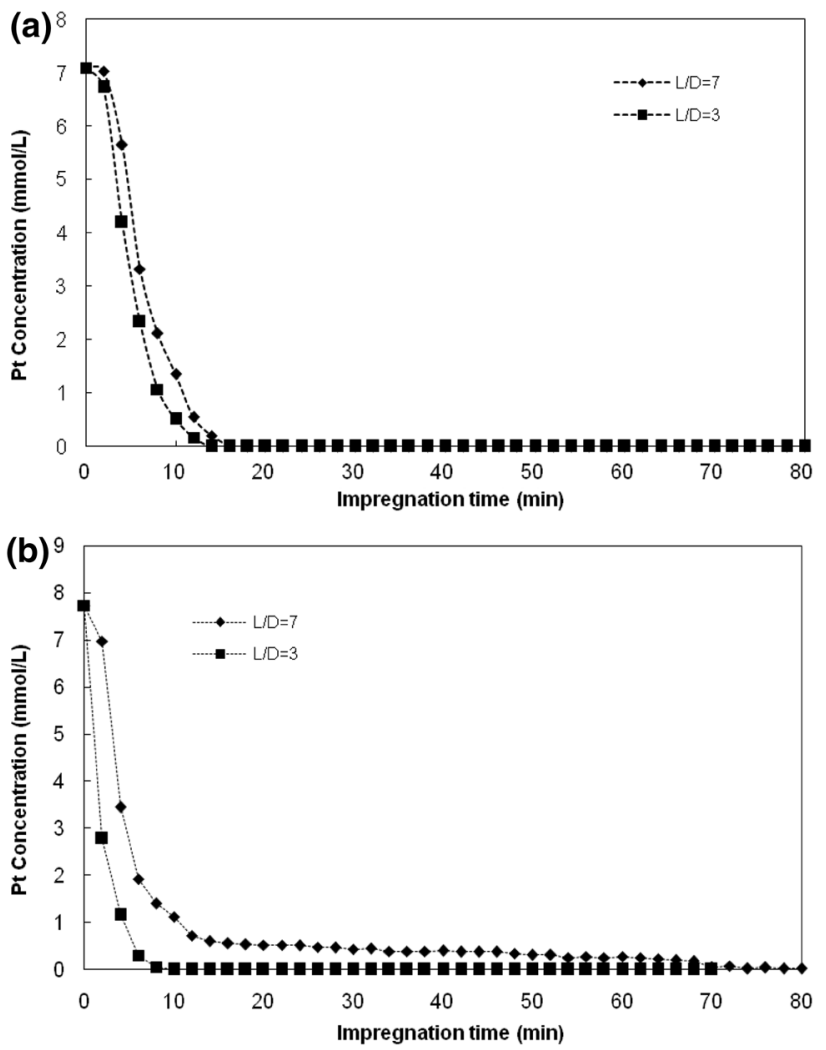

Fig. 3 The effect of impregnation reactor dimension on platinum concentration in impregnation solution for $\mathrm{Pt}-\mathrm{Sn} / \mathrm{Al}_{2} \mathrm{O}_{3}$ catalyst at $\mathrm{pH}$ 1.4 and pump flow rates: a $15 \mathrm{~mL} / \mathrm{min}$, b $40 \mathrm{~mL} / \mathrm{min}$

It is worth mentioning that with acidic solutions, the spatial adsorption profiles tend to become uniform with time because of re-dispersion of platinum at longer adsorption times.

\section{The effect of impregnation reactor geometry}

Given a circulation flow rate and support loading (or a contact time per pass), the velocity of the solution passing support particles, and accordingly mass transfer resistance and deviation from plug flow within the bed, will change with $L / D$ ratio of support bed. In industrial scale, for a packed-bed tower and liquid drum operating at atmospheric pressure, $L / D$ ratio is selected as 3 [3]. In order to investigate the effect of reactor dimension on catalyst synthesis, experiments were performed in fixed-bed vessel with $L / D=3$ and $L / D=7$ using two different pump flow rates (namely 15 and $40 \mathrm{~mL} /$ $\mathrm{min}$ ) and at $\mathrm{pH} 1.4$. Ideally, for a given circulation rate, the Pt concentration-time data points should superimpose for different bed aspect ratios. However, as illustrated in Fig. 3, for reactor with $L / D=3$, platinum concentration in solution vessel declined sharply and reached zero faster, although for each circulation flow rate, the nominal weight-times $(\mathrm{kg} \mathrm{h} / \mathrm{L})$ were the same. However, the ratio of superficial 
velocities for $L / D=7$ to $L / D=3$ is $(7 / 3)^{2 / 3}=1.8$ for a given circulation rate. The lower velocity in the later could result in a lower external mass transfer coefficient and also larger deviation from a plug-flow pattern inside the reactor, and thereby a different concentration-time profile.

A careful look at Fig. 3 (and other dynamic adsorption plots) reveals an initial "delay time" after which the Pt precursor concentration of impregnating solution drops rapidly which is an obvious deviation from the well-mixed batch reactor being considered as the ideal one for uniform impregnation. This time corresponds, roughly, to the time required for the first "charge" of impregnating solution slipped the reactor, that is, the reactor holding time considering collectively the void volume between support particles, quartz fillers, and free-volume within the reactor.

This deviation could be minimized by decreasing the characteristic time of mixing (e.g., residence time within the bed) compared to the characteristic time for adsorption (a function of rate constant of adsorption and initial adsorbate concentration). These conditions could be qualitatively achieved by, for example, increasing recycle rate of impregnating solution or by lowering support loading (equivalent to decreasing the residence time) or increasing competitive ion concentration (equivalent to reducing the effective adsorption rate constant), as confirmed by the above experimental results.

It should be pointed out that this delay does not significantly affect the discussion based on Eq. 6, since both adsorbates experience this deviation to the same extent.

\section{Effect of circulation rate}

The circulation rate is the parameter by which the residence time of impregnating solution over the support bed in each cycle can be controlled. It also affects the flow pattern within the bed and external mass transfer to support particles. In order to investigate its influence, two values for pump flow rates, that is 15 and $40 \mathrm{~mL} / \mathrm{min}$, were selected. The impregnating solution was prepared at $\mathrm{pH}$ 1.4. Time dependence of platinum concentration in impregnating solution is shown in Fig. 4. It illustrates that the concentration of $\mathrm{Pt}$ in impregnation solution decreased with increasing the flow rate. The concentration time lag decreased with increasing pump flow rate because the residence time per cycle decreases with circulation rate, resulting in a closer approach to well-mixed behavior, and thus a lower Pt concentration for a given adsorption time.

At low pump flow rate as impregnating solution passed slowly over the catalyst bed, its residence time in impregnation reactor was long. The deepest color in the bed was observed at the entrance zone with the color front progressing with impregnation time. Because of the strong alumina-CPA interaction, the beneath layers of support
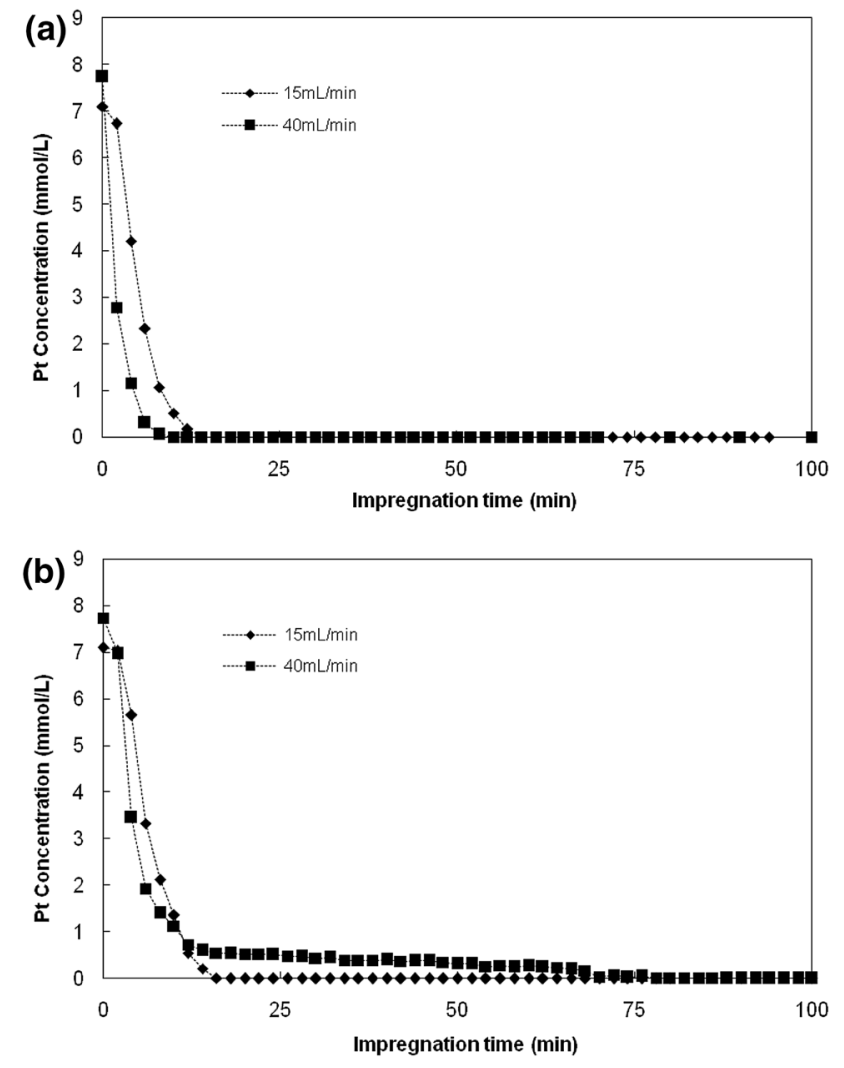

Fig. 4 The influence of circulation rate on platinum concentration in impregnation solution for $\mathrm{Pt}-\mathrm{Sn} / \mathrm{Al}_{2} \mathrm{O}_{3}$ catalyst at $\mathrm{pH} 1.4$ a $L / D=3$, b $L / D=7$

adsorbed more platinum and its concentration in the impregnating solution rapidly approached zero along the bed. With time and continuous passage of impregnating solution over the catalyst bed and subsequent adsorption and desorption, the platinum re-distributed along the support bed until a more uniform platinum distribution was obtained. The redistribution of $\mathrm{Pt}$ is a consequence of equilibrium nature of its adsorption being facilitated in the presence of competitive ions.

When high pump flow rate was used, impregnating solution residence time was short. The color of the bed remained more or less uniform depending on time until equilibrium adsorption being achieved.

\section{Conclusions}

The effect of important parameters (such as $\mathrm{pH}$ of the impregnation solution, circulation flow rate, and height/ diameter ratio) on competitive impregnation in a recycling fixed-bed impregnation reactor was investigated for Pt-Sn/ $\mathrm{Al}_{2} \mathrm{O}_{3}$ catalyst. It was found that appropriate competitive adsorption is necessary to obtain a uniform product. As in 
the present research, the concentration of the competitive ion is about one order of magnitude larger than CPA, initial adsorption of the former in initial time-on-stream is more, which is reversed at longer times on stream due to thermodynamic equilibrium limitation. By increasing $\mathrm{pH}$ and decreasing pump flow rate, rate of adsorption was increased and axial non-uniformity in the bed was enhanced. Uniform support bed was obtained for catalyst synthesis when the performance of the system approached to that of ideal mixed reactor (e.g., at $\mathrm{pH} 1.4$ and 1.5).

Open Access This article is distributed under the terms of the Creative Commons Attribution 4.0 International License (http://creativeco mmons.org/licenses/by/4.0/), which permits unrestricted use, distribution, and reproduction in any medium, provided you give appropriate credit to the original author(s) and the source, provide a link to the Creative Commons license, and indicate if changes were made.

\section{References}

1. Anderson JR, Pratt KC (1985) Introduction to characterization and testing of catalyst. Academic Press, New York

2. Bhasin MM, McCain JH, Vora BV, Imai T, Pujado PR (2001) Dehydrogenation and oxy-dehydrogenation of paraffins to olefins. Appl Catal A G 221:397-419

3. Couper JR, Roy Penney W, Fair JR, Walas SM (2012) Chemical process equipment, selection and design. Elsevier, Amsterdam

4. Ertl G, Knozinger H, Weitkamp J (1999) Preparation of solid catalysts. Wiley-VCH, Weinheim

5. Galarraga C, Peluso E, Lasa HD (2001) Eggshell catalysts for Fischer-Tropsch synthesis modeling catalyst impregnation. Chem Eng J 82:13-20

6. Komiyama M (1985) Design and preparation of impregnated catalysts. Catal Rev Sci Eng 27:341-372

7. Lekhal A, Khinast JG, Glasser BJ (2001) Predicting the effect of drying on supported co-impregnation catalysts. Ind Eng Chem Res 40:3989-3999

8. Lekhal A, Glasser BJ, Khinast JG (2004) Influence of pH and ionic strength on the metal profile of impregnation catalysts. Chem Eng Sci 59:1063-1077

9. Le Page JF, Cosyns J, Courty P (1987) Applied heterogeneous catalysis; design, manufacture and use of solid catalysts. IFP, Technip, France
10. Liu X, Khinast JG, Glasser BJ (2008) A parametric investigation of impregnation and drying of supported catalysts. Chem Eng Sci 63:4517-4530

11. Liu J, Liu C, Ma A, Rong J, Da Z, Zheng A, Qin L (2016) Effects of $\mathrm{Al}_{2} \mathrm{O}_{3}$ phase and $\mathrm{Cl}$ component on dehydrogenation of propane. Appl Surf Sci 368:233-240

12. Masesen TLM, Botman MJP, Slaghek TM (1986) On platinum catalysts of hydrocarbon reactions and the possible role of Pt ions. Appl Catal 25:35-41

13. Neimark AV, Kheifez LI, Fenelonov VB (1981) Theory of preparation of supported catalysts. Ind Eng Chem Prod Res Dev 20:439-450

14. Roth JF, Reichard TE (1972) Determination and effect of platinum concentration profiles in supported catalysts. J Res Inst Catal 20:85-94

15. Sanfilippo D, Miracca I (2006) Dehydrogenation of paraffins: synergies between catalyst design and reactor engineering. Catal Today 111:133-139

16. Tahriri Zangeneh F, Taeb A, Gholivand K, Sahebdelfar S (2015) The effect of mixed $\mathrm{HCl}-\mathrm{KCl}$ competitive adsorbate on Pt adsorption and catalytic properties of $\mathrm{Pt}-\mathrm{Sn} / \mathrm{Al}_{2} \mathrm{O}_{3}$ catalysts in propane dehydrogenation. Appl Surf Sci 357:172-178

17. Takht Ravanchi M, Abedini A, Sahebdelfar S, Mehrazma Sh, Seyyed Shahabi S (2015) Mathematical modeling of platinum and chlorine distributions within $\mathrm{Pt}-\mathrm{Sn} / \mathrm{Al}_{2} \mathrm{O}_{3}$ catalyst prepared by impregnation. Sci Iran C 22:981-991

18. Wei J, Becker ER (1975) The optimum distribution of catalytic material on support layers in automotive catalysis. Adv Chem Ser 143:116-132

19. Yee Fhan NG (2015) Preparation of pellet catalyst with non-uniform metal distribution. Dissertation

20. Zhang Y, Zhou Y, Sheng X, Wan L, Li Y, Xiao Y, Yu B, Zeng Zh (2012) Effect of the competitive adsorbates on the catalytic performance of $\mathrm{Pt}-\mathrm{Sn}-\mathrm{K} / \mathrm{Al}_{2} \mathrm{O}_{3}$ catalyst for isobutane dehydrogenation. Fuel Process Technol 104:23-30

21. Zhang Y, Zhou Y, Shi J, Zhou Sh, Sheng X, Zhang Z, Xiang S (2014) Comparative study of bimetallic Pt-Sn catalysts supported on different supports for propane dehydrogenation. J Mol Catal A Chem 381:138-147

Publisher's Note Springer Nature remains neutral with regard to jurisdictional claims in published maps and institutional affiliations. 